\title{
Hydraulic transport in small livestock farms
}

\author{
Oktyabr Rakhimov ${ }^{1 *}$, Laylo Ashurova ${ }^{1}$, and Fotima Artikbekova ${ }^{2}$ \\ ${ }^{1}$ Karshi engineering-economics institute, Karshi, Uzbekistan \\ ${ }^{2}$ Tashkent Institute of Irrigation and Agricultural Mechanization Engineers, Tashkent, Uzbekistan
}

\begin{abstract}
The article highlights the advantages and benefits of pipeline transport of liquid feed mixtures on small pig farms, the device and the principle of operation and technical characteristics of the improved rotor pump developed by the authors of the article. Methods of experimental research to determine the concentration of feed mixtures, the influence of the shape of the separator on the performance characteristics, the required power and the flow of an improved pump are presented. The results of the experiments showed that one of the bottlenecks limiting the operation of rotary pumps on feed mixtures of increased concentration is the low suction capacity of the pump, that is, the design of the suction pipe of the pump, where an increase in resistance with an increase in the concentration of feed mixtures causes a breakdown of the operating mode and cavitation. To resolve this issue, we used a screw feeder installed in front of the pump suction nozzles. It was found that if the screw feeder provides excess pressure within (about, $0.25 \ldots 0.3) 10^{5} \mathrm{~Pa}$ per suction cavity, the pump operates stably and reliably.
\end{abstract}

Keywords: centrifugal fecal pumps, concentration, volumetric methods, water flow.

\section{Introduction}

Modern pig farming is the world's leading livestock industry; occupying a leading position in the 'meat' balance. In the structure of world meat production, pork ranks first (38.739.7 $\%)$. In Asia, the share of pork in the production of all types of meat is $54.6 \%$, in Europe $51.0 \%$, in Russia $32.4 \%$ [1].

The organization of productive, cost-effective pig breeding on small farms can be successfully solved if it is carried out at a high technical level and with a rational animal feeding.

Different types of feed consistencies have their own characteristics. Dry food does not require additional preparation, it is convenient for distribution, but it increases the dustiness of the air in the pigsty and causes respiratory diseases in pigs. In addition, when the animals are fed only with dry compound feeds, their digestibility decreases by $4 . .6 \%$ compared to the use of wet feed mixtures [2-5].

Dry food is the most efficient, but wet feeding is more effective. That is why, in order to preserve technical means and reduce labor costs for maintaining hygiene, you should use dry food, moistened immediately before feeding the animals [6-8].

\footnotetext{
*Corresponding author: rahmat1959@mail.ru
} 
Feeding with liquid feed has a number of advantages: the time for eating the feed is reduced, the loss of feed is reduced, it becomes possible to use finely ground feed, the uniformity of feed and distribution to the feeders is maintained. With a decrease in eatability in sows, the feeding method allows, which is very important, to regulate the nutritional value of the feed in the same volume of bark mixture [9-11].

Feeding with liquid feed also makes it possible to use one of the most economical and reliable methods of transporting feed - hydromechanical, that is, a method when feed is fed into the feeders through pipes in certain doses. Pipeline transport is highly productive, simple in structure, it can be mounted in buildings of any type, it does not require special aft passages, and it increases work culture [12, 13].

The use of pipeline transport for the transportation and distribution of feed mixtures on pig farms requires the use of special feed-transporting pumps with high reliability. Currently, the industry does not produce special pumps for supplying rational liquid feed mixtures, and the use of pumps from other industries does not give effective results.

Currently, on farms and complexes, the previously produced centrifugal fecal pumps of the $21 / 2 \mathrm{NF}, 4 \mathrm{NF}$, 6NF types, the NPG-2, NPG-3, 4PS-9 sand pumps, 8FS-17 mixing pumps, and the S-296 piston concrete pumps are widely used, gear pumps D-159-V, screw pumps VNM-18-2, VNM-15-100 and other pumps. But, as noted above, all these pumps are not intended for feeding feed mixtures and they require structural changes, and also, the rotary pump of the Kamur company (Sweden) has become of widespread use while pumping various high-viscosity slurries $[14,15]$. Therefore, many farms use various converted and homemade pumps.

Therefore, the development of a pump used for feeding feed mixtures with low moisture content is very important. Based on this, the purpose of the study is to develop a new energy-saving design of a rotary pump that allows transporting feed mixtures of increased concentration and low humidity.

\section{Methods}

The design of the pump used for pumping liquid feed mixtures was determined by its rheological properties. Depending mainly on the concentration of the dry component. Concentrations of feed mixtures were determined by taking feed mixtures of a known volume from a mixer, followed by removal of moisture, drying and weighing the dry residue. To determine the effect of the shape of the spacer on the performance, the pump is equipped with three replaceable flat, convex and wedge shaped spacers. An IS-203.4 sump was used to determine the required power. The pump flow was determined by volumetric methods using a measuring tank.

\section{Results and discussion}

Based on the analysis of the designs and performance of the pumps used for the supply of viscous slurries, as well as the requirements imposed on them and taking into account the preliminary expirations, the design and technological scheme of a two-rotor rotary pump was adopted as an object of research [16-19], and a rotary pump with a screw feeder was developed for supplying liquid feed mixtures by pipe distributor. 


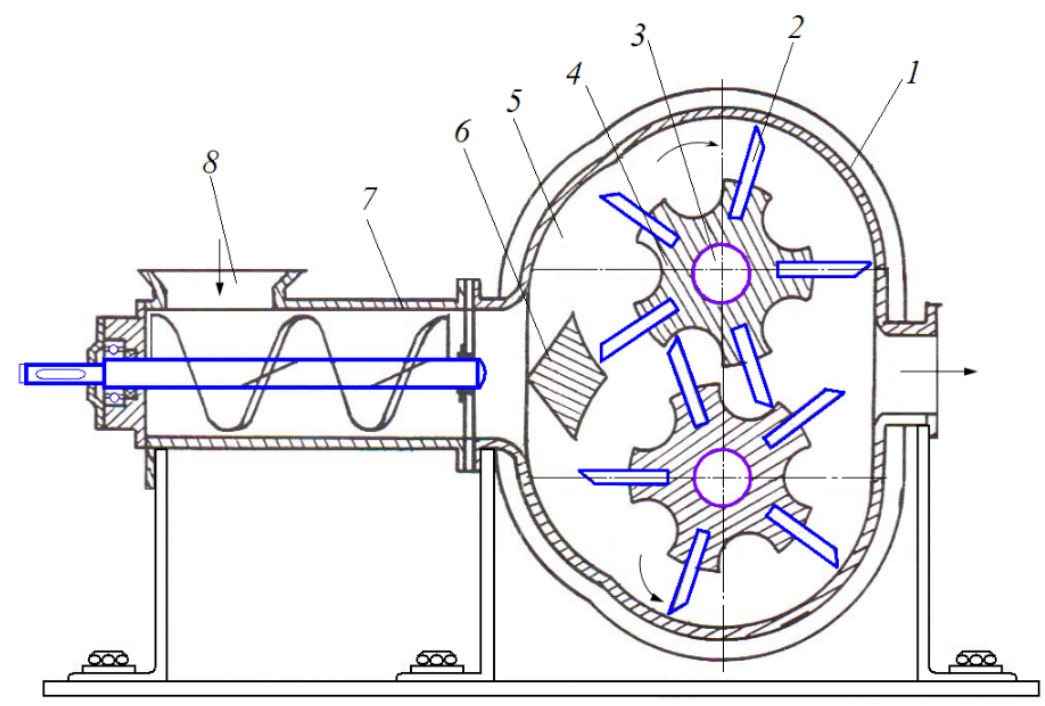

Fig. 1. The proposed scheme of a rotary pump with a screw feeder: 1 - case; 2 - blade; 3 - shaft; 4 rotor; 5 - additional chamber; 6 - stream splitter; 7 - screw feeder; 8 - loading mouth.

The pump consists of an assembled casing 1, in which two collapsible rotors 4 rotate in opposite directions. The rotors are rigidly connected to the shaft 3 , which is mounted on ball bearings in lateral struts connected to the casing by bolts. One of the shafts (rotors) is connected to the motor through a gearbox and is driven. The second shaft (rotor) is driven with a coordinated rotation from the drive shaft using gear wheels, the gear ratio of which is equal to one. The gears are housed in an oil bath chamber. On each of the rotors 4 , five blades 2 are fixed, located at equal distances around the circumference. When the rotors turn, they enter special recesses, thereby ensuring separation of the high pressure zone from the low pressure zone. Elimination of leakage into the surrounding seat and prevention of the ingress of feed mixtures into the oil bath and bearings is ensured by gland seals.

The working part of the pump consists of two modular rotors, which rotate with the same angular velocity, but in opposite directions. The consistency of the movement of the rotors is ensured by means of a gear train with the number $i=1$, placed outside the working chamber. The displacers are special blades 2 mounted on the rotor. Displacers, they are also cut-off devices, one by one enter the receiving chamber, cut off certain volumes of mass when interacting with the body and move them into the pressure chamber. After the cut-off volume is moved to the pressure chamber, the displacers return again to the receiving chamber to repeat the cycle, ensuring closure and minimal mass transfer from the pressure chamber to the suction chamber.

In addition, the pump is equipped with a flow divider 5, which includes additional resistance to rotation of the pump rotor due to the effect of the supplied mass. It is installed on the pump inlet and serves to change the direction of flow in the direction of the rotor rotation. At the same time, the supplied mass does not create braking resistance forces and gives up its kinetic energy, acquired from the screw feeder, to the rotor, thereby reducing the required pump power. In addition, the spacer 5 is made with an adjustable angle between the edges. It is advisable to install a flow divider in the additional pump chamber 6.

The results of the experiments showed that one of the bottlenecks limiting the operation of rotary pumps on feed mixtures of increased concentration is the low suction capacity of the pump, that is, the design of the suction pipe of the pump, where an increase in resistance with an increase in the concentration of feed mixtures causes a breakdown of the 
operating mode and cavitation. When cavitation occurs, the pumps are unstable, there is a sharp drop in head and flow. To solve this issue, we used a screw feeder installed in front of the pump suction nozzles.

The main reason for the deterioration of the pump performance when feeding a feed mixture with low moisture content is a decrease in the speed of the feed mixture in the suction pipe of the pump. When testing the pump, the maximum volumetric efficiency is ( $\mu$ $=0.79$ ) when pumping feed families with a moisture content of $68 \%$ with a pressure in the discharge line of $0.45 \mathrm{MPa}$ was obtained at an average speed of the feed mixture in the suction pipe of the pump equal to $\mathrm{v}_{\mathrm{cp}}=0.42 \mathrm{~m} / \mathrm{s}$ (Figure 2.)

The change in the flow rate $\mathrm{QH}$, the required power $\mathrm{N}$ and the efficiency of the pump $\mu$ depending on the pressure in the discharge line at a constant rotor speed is graphically shown in Figs 3, 4.

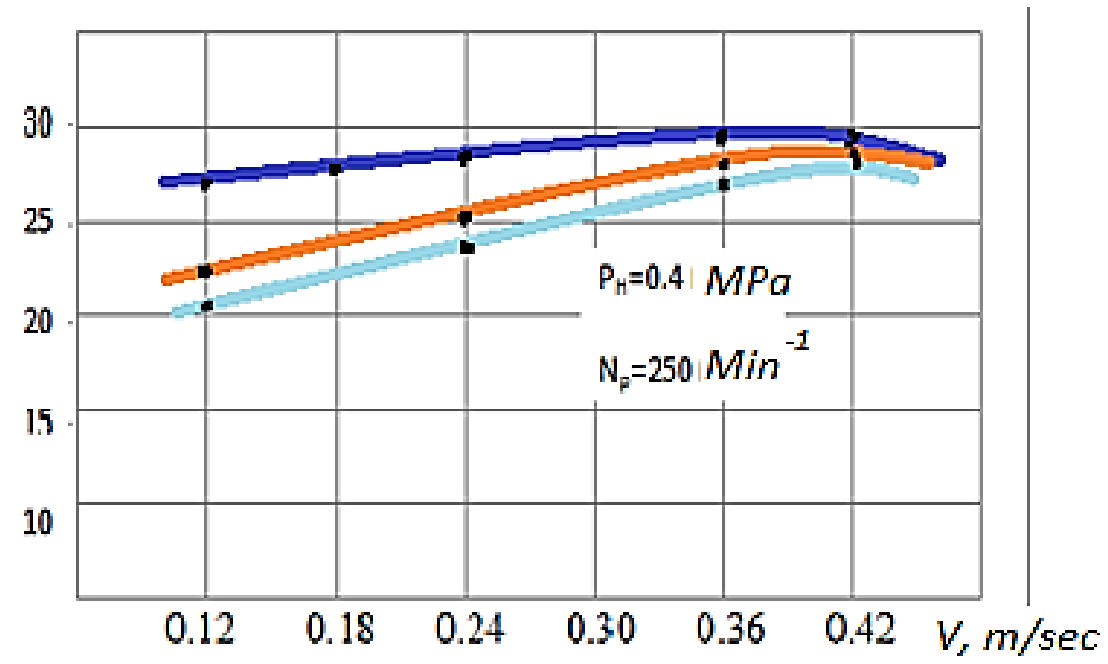

Fig. 2. Dependence of the flow rate $(\mathrm{QH})$ of the pump on the speed of feed mixtures $(\mathrm{v})$ in the suction pipe of the pump.

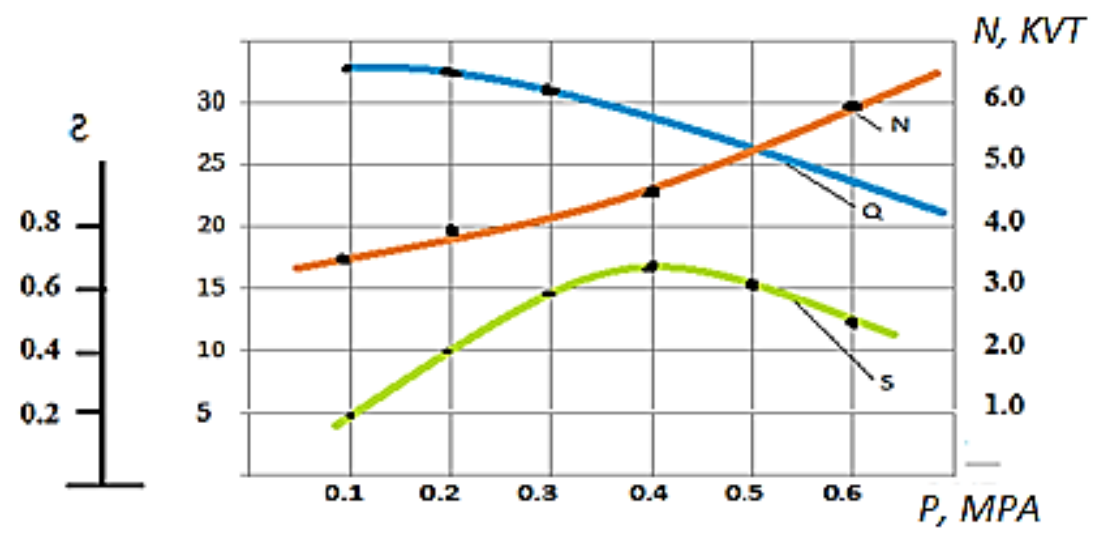

Fig. 3. Features of a rotary pump with a screw feeder while feeding mixtures with grass paste with a moisture content of $72.8 \%$. 


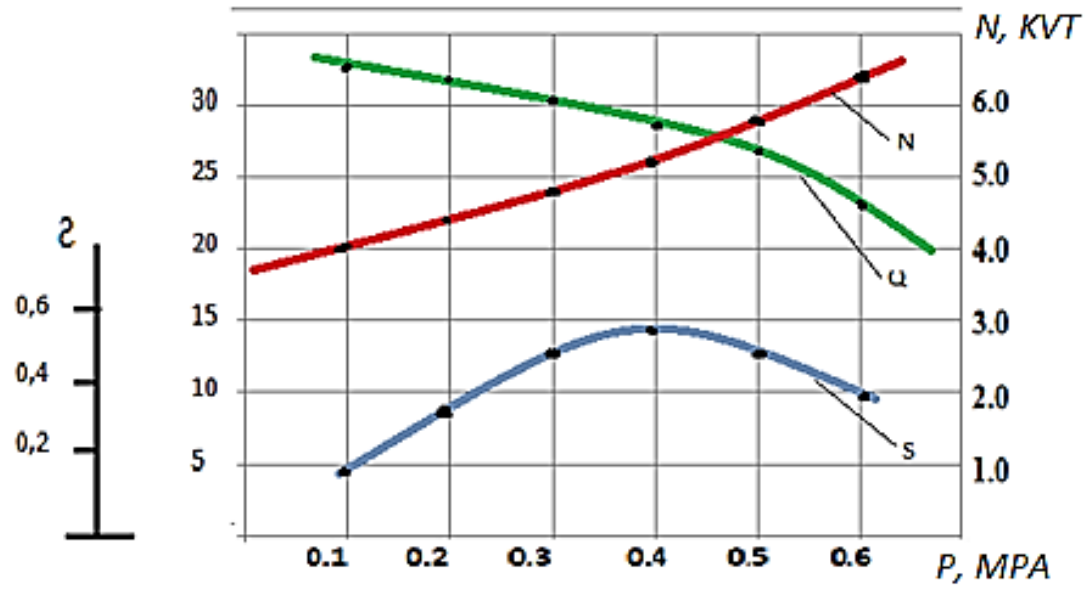

Fig. 4. Characteristics of a rotary pump when feeding concentrate feed mixtures with a moisture content of $68 \%$.

The study shows that the speed of the feed mixture in the suction cavity of the pump when feeding the feed mixture with a moisture content of $68 \%$ is $0.12 \mathrm{~m} / \mathrm{s}$, and the pump flow rate is $21.5 \mathrm{~m}^{3 / \mathrm{h}}$, that is, $26 \%$ lower than the feed mixture with a moisture content of $80 \%$. To improve the operation of the pump when feeding feed mixtures with low humidity, additional backwater is required in front of the suction nozzles of the pump, which can be created using a screw feeder. It has been established that the value of the feed mixture velocity in the suction line depends on the productivity of the screw feeder and the crosssectional area of the pump inlet pipe. The productivity of the screw feeder was regulated by changing the rotational speed of its screw using replaceable sprockets. It was found that if the screw feeder provides excess pressure within (about, $25 \ldots 0.3$ ) $10^{5} \mathrm{~Pa}$ per suction cavity, the pump works stably and reliably.

The application of this improved pump in farm production requires careful learning. This requires the use of the most innovative $[20,21]$ and modern pedagogical [22] technologies of teaching, online training of farmers and telecommunication training projects [23]. In such teaching, lectures are not in a simple traditional form but are problematic and modern lectures [24-26] should be conducted using interactive methods, ensuring the activity of the audience. At the same time, of course, it is important to address the audience with problematic questions during the lesson, to direct them to creative and scientific thinking by creating problematic situations in the lecture. In addition, the creation of online training courses, including the use of technologies such as project style [27], scientific and creative thinking, enriching the online course module platform with electronic resources [28], including video and audio lectures, gives great results. In short, there is a need to pay more attention to education in the use of improved pumps on farms. It is no coincidence that the quality of education is the quality of life [29-34].

\section{Conclusions}

1. Our preliminary studies of this pump showed that a rotary pump of this design works stably at a feed mixture moisture content of $70 \%$ or more. However, the introduction of grass paste or juicy components into the feed mixture sharply increases its viscosity, concentration and at the same time reduces the fluidity of the feed mixture by 10 times or more. In this case, the performance of the pump deteriorates, that is, the flow and head of 
the pump decrease. To ensure reliable transportation of feed mixtures of low moisture content with green paste, it is necessary to use forced feeding. For this, a screw feeder 7 was installed at the pump inlet.

2. On the basis of theoretical and experimental studies, the need to supply the pump with a flow divider was substantiated, which excludes additional resistance to the rotation of the pump rotor due to the effect of the supplied mass. The optimal angle $\alpha$ between the working edges of the separator has been established. For this pump, the angle $\alpha$ is 90.1000 with a rotor diameter of $260 \mathrm{~mm}$. The use of this design of the separator allows reducing the required drive power by $20 \%$ compared to pumps without a separator.

3. Based on the results of the research, the following optimal parameters and operating modes of the pump were determined: flow rate $30 \mathrm{~m}^{3} / \mathrm{h}$, discharge pressure $0.4 \mathrm{MPa}$, pump rotor speed $250 \mathrm{~min}-1$, required power $6.3 \mathrm{~kW}$, specific energy consumption of the technological process not more than $0.21 \mathrm{KWh} / \mathrm{m}^{3}$, labor time spent on the technological process $0.034 \mathrm{~h}$.

4. The use of a new rotary screw pump with screw feeders on small pig farms allows to reduce the metal consumption by 2 times, the energy consumption of the technological process by at least 3.5 times and increase the productivity by 2 times in comparison with the existing centrifugal pumps.

5. Before implementing this improved feed pump and other new techniques on farms, it is advisable to train farmers in online training courses on the basis of modern innovative pedagogical technologies.

\section{References}

1. E. A. Kryshtop, Improving the productive qualities of pigs by mobilizing the internal reserves of the body (Volgograd, Russia, 465, 2011)

2. K. I. Knyazev, Intensive meat feeding of pigs (Moscow, Russia, 222, 1979)

3. A. I. Devyatkin, Rational use of feed in industrial production (Moscow, Russia, 343, 2016)

4. L. G. Boyarsky, Production and use of feed in industrial production, (Moscow, Russia, 542, 2018)

5. Scientific foundations of complete feeding of farm animals, Sat scientific works (Moscow, Russia, 145, 2017)

6. Kh. Kh. Gubeidullin, Improvement of technologies and means of mechanization of distribution of liquid and semi-liquid feed (Ulyanovsk, Russia, 351, 2005)

7. M. R. Baxter, Design of new feeder for pigs, Farm Building Progress, 19-22 (1989)

8. E. Roth, Hachlesefiir Sauenhalter und Schweinmaster Agrar, Ubers, 40(9), 66-69 (1989)

9. V. I. Alexandrov, Methods for reducing energy consumption in the hydraulic transport of high concentration mixtures (SPGGI (TU), St. Petersburg, Russia, 117, 2000)

10. V. P. Dokukin, Improving the efficiency of the pipeline hydro transport system (SPGGI (TU), St. Petersburg, Russia, 105, 2005)

11. Y. D. Tarasov, V. P. Dokukin, A. K. Nikolaev, Pressure hydro transport installations in the mining industry, Pressure Hydraulic Plants in the Mining Industry, (SPGGI (TU), St. Petersburg, Russia, 104, 2008)

12. A. A. Utkin, Pig feeding systems (GNU VNIIMZh Russian Agricultural Academy, Podolsk, Russia, 226, 2011)

13. F. Abduosiev, Prospects for the development of animal husbandry taking into account scientific and technological progress, (Internet-version of the publications of Charkhi Gardun LLC, 2012) 
14. V. I. Klimov, Hydrotransport of fibrous materials in pulp and paper production (Moscow, Russia, 1971)

15. V. I. Klimov, Rotary lobe pumps for high-viscosity dairy products (Moscow, Russia, 1970)

16. O. D. Rakhimov, B. M. Khudoyorov, F. M. Mamatov, I. Ergashev, Pump for the supply of liquid feed mixtures, 1089, Patent No 5149, Uzbekistan Republic (1998)

17. O. D. Rakhimov, B. M. Khudoyorov, F. M. Mamatov, U. B. Eshkobilov, Feed pump, 1090. Patent No 5150, Uzbekistan Republic (1998)

18. O. D. Rakhimov, Zh. Kh. Togaev, A. Kh Khuzhakulov, Improved feed pump for farms, Akademy, 6(45), 25-27 (2019)

19. O. D. Rakhimov, Zh. Kh Togayev, A. Kh. Khuzhakulov, Usovershenstvovannyy kormonasos dlya fermerskikh khozyaystv, Academy, 6(45), 25-27 (2019)

20. O. D. Rakhimov, Y. K. Manzarov, A. E. Karshiyev, Description of pedagogical technologies and technology of problem-based learning, Problemy sovremennoy nauki i obrazovaniya, 2(147), 59-62 (2020) DOI: 10.24411/2304-2338-2020-10201

21. O. D. Rakhimov, L. Ashurova, Types of modern lectures in higher education, technology of their design and organization, Problemy sovremennoy nauki i obrazovaniya, 12(157), 41-46 (2020)

22. O. D. Raximov, O. M. Turgunov, Modern educational technologies (Science and Technology, Tashkent, Uzbekistan Republic, 205, 2013)

23. O. D.Raximov, S. S. Eshev, The importance of the telecommunication project on education system, in proceedings of International scientific conference Topical issues of the development of science in the world, Moscow, Russia, 2019

24. O. D.,Raximov, Y. K. Manzarov, A. E. Qarshiyev, Sh. A. Sulaymanova, Description of pedagogical technology and problematic teaching technology, Problemy sovremennoy nauki i obrazovaniya, 2(147), 59-62 (2020) DOI: 10.24411/2304-2338-2020-10201

25. O. D. Rakhimov, Necessity of live modern lectures in higher education and its types, Science problems, 10(58), 60-64 (2020) DOI: 10.24411/2413-2101-2020-11002

26. O. D. Rakhimov, B. F. Nazarov, M. S. Sapaev, Modern lectures in higher education, (TUIT Karshi branch, Karshi, Uzbekistan Republic, 2012)

27. O. D. Raximov, Innovative pedagogical technologies: project style as a technology that improves the quality of education (TUIT Karshi branch, Karshi, Uzbekistan Republic, $80,2013)$

28. O. D. Raximov, Requirements and technology for creating e-learning resources, Sovremennoe obrazovane (Uzbekistan), 202, 45-50 (2016)

29. O. D. Raximov, Y. Kh. Manzarov, M. Keldiyarova, A. H. Xudjakulov, Modern lectures and methods of organizing problematic lectures, Science problems, 2(50), 45-48, (2020) DOI: 10.24411/2413-2101-2020-10201

30. O. D. Rakhimov, L. Ashurova, Types of modern lectures in higher education, technology of their design and organization, Problemy sovremennoy nauki i obrazovaniya, 12(157), 41-46 (2020)

31. O. D. Raximov, Quality of education-quality of life (Karshi branch of Tashkent University of Information Technologies, Karshi, Uzbekistan Republic, 46, 2015)

32. A. R. Khafizov, F. F. Kamaletdinov, A. B. Yakushkina, I. V. Nedoseko, Construction regulatory systems to protect the banks of the Ufa river in the area of Ufa water intake, Izvestiya KGASU, 1(51), 118-127 (2020)

33. R. Kh. Mukhametrakhimov, I. R. Aliullova, Improvement of the quality control system for expansion joints with rubber compensators during the repair of bridge constructions, Izvestiya KGASU, 3(53), 47-55 (2020) 
34. R. Kh. Mukhametrakhimov, A. A. Panchenko, Features of the quality control system for the construction of outdoor water supply and sewerage networks, Izvestiya KGASU, 4(42), 360-367 (2017) 